\title{
Agenda climática do município de São Paulo: contribuição de redes transnacionais de governos locais
}

\author{
Climate agenda of the city of São Paulo: \\ contribution of transnational networks of local governments
}

\author{
Adalberto Gregório Back \\ Doutorando em Ciência Política, Universidade Federal de \\ São Carlos - UFSCar; Bolsista da Fundação de Amparo \\ à Pesquisa do Estado de São Paulo - FAPESP \\ e-mail: backgregor@gmail.com
}

Recebido: $16 / 05 / 2012$ Aceito: 11/10/2012
RESUMO Este trabalho tem por objetivo entender o processo de formação e incorporação da agenda climática na política ambiental e urbana do município de São Paulo. Para tanto, com base nos pressupostos teóricos de agenda-setting do modelo de Kingdon, realizamos: revisão bibliográfica da literatura internacional sobre o modo de atuação da campanha CPC da rede transnacional de governos locais, ICLEI; análise qualitativa de entrevistas com alguns atores que participaram no processo de formulação da lei e levantamento das ações locais do município convergentes com o enfrentamento das mudanças climáticas globais.

PALAVRAS-ChAVE Mudança climática global; Formação da agenda climática; Município de São Paulo; Redes transnacionais de governos locais.

ABSTRACT This study aims to understand the process offormation and incorporation of the climate agenda in environmental and urban policies of city of São Paulo. Therefore, based on the theoretical assumptions of agenda-setting model of Kingdon, we make: a review of international literature about the action of Cities for Climate Protection Campaign of the transnational network of local governments ICLEI; qualitative analysis of interviews with some actors who participated in the formulation of the law and analisys of the local actions convergent to tackle global climate change.

KEYWORDS Global climate change; Agenda-setting of climate change; Municipality of São Paulo; Transnational networks of local governments.

\section{Introdução}

Este trabalho visa compreender o processo de formação e incorporação da agenda climática na política ambiental e urbana do município de São Paulo. Com esse propósito, investigamos a relação que as redes transnacionais de governos locais exerceram na inserção da questão climática na agenda decisional do governo do município de São Paulo. 
Para tanto, utilizamos como referencial teórico a abordagem de múltiplos fluxos de Kingdon. De acordo com essa abordagem, o ingresso de uma questão na agenda governamental como um problema que desperta a atenção e esforços de formuladores de políticas ocorre quando há uma junção de três fluxos decisórios distintos e independentes: são eles o fluxo de problemas (problems); fluxo de soluções ou alternativas (policies); e fluxo da dinâmica política (politics).

O trabalho está dividido em 4 seções. Na primeira seção, apresentamos mais detalhadamente o aporte teórico que guia a análise sobre a inserção da agenda climática no município de São Paulo.

Na segunda e na terceira seções, nos servindo de ampla bibliografia nacional e internacional, realizamos um mapeamento das principais redes de governos locais observando como buscam gerar soluções, alternativas e incentivos aos governos locais para o tratamento da mudança climática global, dando especial atenção aos modos de atuação da Campanha Cidades para Proteção do Clima da rede ICLEI e na rede das 40 maiores cidades do mundo em liderança climática, o C40. Afinal, O município de São Paulo integra a comitê executivo do ICLEI desde 2005, e também faz parte da direção executiva do C40, desde 2007, tendo sediado o seu $4^{\circ}$ encontro de cúpula (C40 São Paulo Summit), em 2011.

Na quarta seção, observamos o processo de inserção da agenda climática no município de São Paulo. Para tanto, realizamos análise qualitativa sobre os seguintes materiais empíricos: levantamento de várias políticas urbanas e ambientais do Município, empreendidas entre 2003 e 2009, e que têm interface no enfrentamento às mudanças climáticas globais; entrevistas com alguns atores que participaram no processo de formulação da lei; bem como, documentos oficiais, tais como a Portaria de adesão da Secretaria do Verde e Meio ambiente ao ICLEI, decretos de constituição e atas do Comitê de mudanças climáticas, bem como a própria lei 14.933.

\section{Inserção da Questão Climática na Agenda de Governos Subnacionais}

A geração de informações sobre as mudanças climáticas são de extrema importância para abordar adequadamente os fatores de risco, em especial para as cidades que concentram grande volume de população e bens materiais. Tal conhecimento é necessário para que os governos, seja em nível nacional ou subnacional, possam elaborar políticas públicas de mitigação de GEE e de adaptação aos impactos das mudanças climáticas.
Os indicadores climáticos e suas consequiências ambientais, sociais e econômicas ajudam os decisores políticos a perceberem a questão como um problema passível de entrar na agenda governamental. No entanto, seguindo o modelo de Kingdon (2003) do processo de formação da agenda, tais indicadores não seriam suficientes para a formulação de uma política pública. $\mathrm{O}$ modelo de multiple stream indica que a mudança ou inserção de uma questão na agenda governamental se dá quando há uma convergência entre três fluxos decisórios distintos. São eles, os fluxos de: problemas (problems); soluções ou alternativas (policies); e dinâmica política (politics).

O fluxo decisório (problems) se caracteriza pela definição de uma questão (conditions) que será objeto de atenção dos formuladores de políticas, dentre várias questões possíveis. Para o autor, uma questão é uma condição social percebida, mas que não necessariamente desperta em contrapartida uma ação dos formuladores de políticas. Para uma questão se transformar em problema e, portanto, chamar a atenção dos participantes de um processo decisório, dependerá de como essa questão será definida e interpretada. Esse processo de seleção de questões para a agenda decisional é subsidiado geralmente por três mecanismos: indicadores quantitativos e qualitativos que apontam para a existência de uma questão a qual pode ser percebida como problemática pelos formuladores de políticas; eventos ou crises de grande magnitude que concentram a atenção num determinado assunto; e, por fim, os feedbacks sobre programas em desenvolvimento no governo, tais como o acompanhamento da implementação, o cumprimento de metas e o surgimento de conseqüências não antecipadas.

No fluxo de soluções e alternativas observa-se que essas são geradas em comunidades compostas por especialistas (policy communities) - pesquisadores, assessores parlamentares, acadêmicos, funcionários públicos, analistas pertencentes a grupos de interesses, partidos políticos, entre outros - que compartilham uma preocupação em relação a uma área (policy area) e/ou em relação a uma questão (condition) específica que pode ou não ser objeto da atenção de decisores políticos (Kingdon, 2003). A policy community também se caracteriza por contar com um grupo limitado de participantes (includente/excludente) que interagem de maneira frequente e com alta qualidade sobre os assuntos relacionados às questões de uma política (Rhodes, 2008).

No processo de seleção de soluções e alternativas (policy stream) para um problema ou questão competem entre si distintas interpretações que podem ser confrontadas ou combinadas com novas propostas, 
ou ainda podem ser descartadas. Nesse processo competitivo de seleção, as ideias com maiores chances de serem aceitas pelos decisores de políticas são as que se mostram viáveis do ponto de vista técnico, têm custos toleráveis, e gozam da aceitação do público em geral.

No fluxo político (dinâmica política) (politics stream), as coalizões são construídas a partir de um processo de barganha e negociação política. Nesse fluxo, três elementos exercem influência sobre a agenda governamental: o humor nacional, as forças políticas organizadas, e as próprias mudanças dentro do governo.

O "humor" nacional (national mood) ou "clima" nacional se caracteriza por uma situação na qual diversas pessoas compartilham as mesmas questões durante um determinado período de tempo. Essa conjuntura pode trazer incentivos aos atores do processo decisório a promover inserção de alguns problemas na agenda decisória, caso percebam-nas em um humor nacional favorável.

As forças políticas organizadas, exercidas principalmente pelos grupos de pressão, sinalizam aos formuladores de políticas se determinada questão é passível de consenso ou conflito na arena política. Caso os grupos de interesse e outras forças organizadas estejam em consenso em relação a uma proposta, o ambiente se torna altamente propício para uma mudança nessa direção. De outro lado, quando há grupos de interesse contrários a uma determinada proposta haverá maiores custos para a sua inserção na agenda governamental.

A introdução de novos itens na agenda governamental, bem como o bloqueio ou restrição da permanência de outras questões, pode ocorrer quando há alterações dentro da própria estrutura do governo, seja por: mudanças de gestão; mudanças de pessoas em posições estratégicas dentro da estrutura governamental (turnover); mudanças na composição do Congresso; e mudanças na chefia de órgãos e de empresas públicas.

A geração de informações científicas sobre as causas e possíveis consequências das alterações climáticas são de fundamental importância para introduzir a agenda climática tanto em governos nacionais como subnacionais. Afinal, as informações científicas permitem que os decisores de políticas possam perceber a questão climática como um problema. Porém, as informações científicas, por si só, não garantem a adoção da agenda climática pelos governos. Para que isso ocorra é preciso que sejam apresentadas soluções e alternativas viáveis do ponto de vista técnico, com custos toleráveis e com boa aceitação do público em geral.
No nível subnacional, algumas redes transnacionais de governos locais têm contribuído para inserção da agenda climática na agenda governamental de cidades em todo o mundo.

\section{Redes Transnacionais de Governos Locais}

As áreas urbanas são importantes lócus para o tratamento das mudanças climáticas globais por quatro motivos fundamentais: 1) os entraves políticos no âmbito da Convenção do Clima para a definição de um acordo efetivo e legalmente vinculante de redução das emissões globais de Gases de Efeito Estufa (GEE) entre os Estados-nação; 2) as áreas urbanas contribuem com taxas elevadas de emissões de GEE; 3) os impactos decorrentes das mudanças climáticas são sentidos principalmente no âmbito local/regional; e, por fim, 4) os governos locais gozam de competências político-administrativas chave para o enfrentamento às mudanças climáticas tanto relacionadas à mitigação de GEE quanto à adaptação frente aos inevitáveis impactos (Martins e Ferreira, 2011; Un-Habitat, 2011; World Bank, 2010; Ostrom, 2010; Van Staden, 2010; Satterthwaite, 2008; Betsill e Bulkeley, 2007, 2006, 2004; Bulkeley e Betsill, 2003).

Levando em consideração a importância das cidades para o enfrentamento às mudanças climáticas globais, a partir da década de 90 começaram a se formar redes transnacionais de governos locais com o propósito de viabilizar ações para tratar das mudanças climáticas globais nesses níveis de governo, bem como sensibilizar as lideranças locais à questão climática, fomentando sua introdução na agenda governamental.

Entre as redes transnacionais que se destacam no enfrentamento às mudanças climáticas podemos citar a Climate Alliance; o ICLEI - Local Government For Sustainability, com o programa Cities for Climate Protection Campaign (CCPC); o International Solar Cities Initiative (ISCI); o Wolrd Mayors Council for Climate Change; a United Cities and Local Government (UCLG); e o C40 - Large Cities Climate Leadership Group (Vargas e Rodrigues, 2009). Faremos uma breve apresentação das redes, enfocaremos a atuação da Campanha Cidades para Proteção do Clima do ICLEI, pois essa teve papel importante no processo de formulação da política climática do município de São Paulo.

A rede Climate Alliance foi fundada em 1990 com o objetivo de proteção do clima do planeta. Atualmente conta com mais de 1500 cidades, municipalidades ou distritos em 17 países na Europa (Climate Alliance, 2011). A rede também permite a participação de ONG's, governos regionais e outras 
organizações na categoria de membros associados. Ao aderir à rede os governos e entidades participantes se comprometem a: 1) reduzir suas emissões de $\mathrm{CO} 2$ em $10 \%$ a cada 5 anos; 2) diminuir pela metade suas emissões per capita até 2030 (linha de base em 1990); 3) apoiar a proteção de florestas tropicais, evitando o consumo de madeira tropical; 4) apoiar projetos e iniciativas de comunidades indígenas parceiras (Kern e Bulkeley, 2009).

Para conseguir seus objetivos a Climate Alliance realiza workshops, publicações e troca de experiências entre seus membros; apoio à formulação e implementação de políticas locais de clima; atua como lobby perante os governos nacionais, internacionais e União Européia, para melhorar as condições de implementação de política locais relacionadas às mudanças climáticas.

A rede Internacional Solar Cities Initiative (ISCI) foi criada em 2003 por cientistas da área de energia solar, convencidos de que essa fonte de energia pode ser a solução para os problemas de mitigação de GEE. O objetivo da rede é unir esforços de cientistas com iniciativas do poder público para apoiar a sociedade na transição a um sistema mais sustentável de uso de energia (ISCI, 2011). Para isso, promovem congressos para apresentação e discussão de aplicações práticas no setor de energia solar.

A rede United Cities and Local Governments (UCLG), sediada em Barcelona, foi criada em 2004. Seus objetivos estão relacionados à promoção da democracia nos governos locais; cooperação internacional entre os municípios e maior representação destes na governança mundial. Atua com três programas nas áreas de apoio à descentralização em países em desenvolvimento, estratégias de desenvolvimento das cidades e redução de risco de desastres. A rede UCLG atua sobre a redução da vulnerabilidade aos riscos através do programa Partnership for Urban Risk Reduction (PURR) (UCLG, 2011).

Conjuntamente com outras redes transnacionais de governos subnacionais: "Earthquake and Megacities Initiative, Metropolis, CityNeto, ICLEI Local Governments for Sustainability", a rede UCLG tem o objetivo de difundir a consciência sobre redução de riscos nas regiões, construir capacidades nos níveis locais em previsão e gerenciamento dos riscos, transferência de tecnologia e formulação de estratégias sustentáveis para redução do risco de desastres. Além disso, a rede UCLG tem atuado, juntamente com o ICLEI, como observadora nas negociações de Mudanças Climáticas. Atualmente a rede reúne mais de mil municípios e associações de governos municipais presentes em 136 países dos 191 países-membro da ONU.

O World Mayors Council for climate Change foi fundado em dezembro de 2005 pelo prefeito da cidade de Kyoto (Japão), Yorikane Masumoto, logo após o Protocolo de Quioto entrar em vigor. Seus objetivos são de reconhecimento e envolvimento de Prefeitos em esforços multilaterais face às alterações climáticas. A rede que iniciou com apenas 12 membros atualmente conta com mais de 60 líderes de cidades de todos os continentes (WMCCC, 2011).

A rede C40 teve início em 2005, quando o prefeito de Londres convidou mais 17 representantes de grandes cidades para discutir formas de unirem forças para enfrentar o desafio das mudanças climáticas. Nesse encontro, os 18 representantes reconheceram a necessidade de ação conjunta e cooperação para redução de GEE, e se comprometeram a trabalharem juntos para alcançar esse objetivo. Em agosto de 2006, a iniciativa passou a contar com o apoio e cooperação da Clinton Climate Initiative (CCI). Com essa parceria a rede então foi batizada de C40 - Large Cities Climate Leadership Group (C40 cities, 2011). A $\mathrm{CCI}$ auxilia as cidades do C40, prestando assistência técnica no desenvolvimento de projetos nas áreas de redução do consumo de energia e ganhos de eficiência através de readaptações em edifícios públicos e privados, bem como nos sistemas de iluminação pública, reduzindo emissões; gerenciamento de resíduos sólidos; programas de transportes de baixa emissão de carbono; criação de normas na construção civil para induzir melhor eficiência energética; apoio financeiro, apresentação de fornecedores e prestadores de serviços especializados; partilha de informações e conhecimento sobre programas bem sucedidos e replicáveis; ferramentas de medição de GEE das cidades.

Atualmente a rede $\mathrm{C} 40$ conta com a participação das 40 maiores cidades do mundo como membros plenos e outras 19 cidades como afiliadas. Como dito acima, somando-se o PIB das cidades-membro do $\mathrm{C} 40$, a rede estaria posicionada em terceiro lugar no ranking de maiores produtores de riqueza, e na terceira colocação no que diz respeito às emissões de GEE, atrás apenas da China e dos EUA (World Bank, 2010).

\section{Campanha Cidades para Proteção do Clima da Rede ICLEI}

Uma das maiores redes transnacionais de governos locais, e a mais estudada delas, segundo Toly (2008), é $o$ International Council for Local Environment Initiative (ICLEI) - chamado apenas de Local Government for sustainability. Foi criada em 1990 a fim de representar 
internacionalmente as preocupações ambientais dos governos locais (Betsill e Bulkeley, 2006). Em 25-26 de janeiro de 1993, em Nova Iorque, o ICLEI organizou o encontro internacional "1st Municipal Leaders Summit on Climate Change (Primeira Cúpula de Líderes Municipais em Mudanças Climáticas) quando foi criada a campanha para a proteção do clima das cidades, a Cities for Climate Protection Campaign (Cidades para Proteção do Clima) (ICLEI, 2011). Foram estabelecidos quatro objetivos para esta Campanha: 1) fortalecimento do compromisso local com as reduções de emissões urbanas de GEE; 2) disseminação de ferramentas de planejamento e monitoramento para determinar custo-efetivo de políticas de redução de emissões; 3) fomento à pesquisa e desenvolvimento de melhores práticas e projetos pilotos nos municípios; 4) atuar como lobby para que as camadas nacionais e internacionais incluam as ações de nível municipal no plano de ação nacional e nas deliberações internacionais (ICLEI 1993 apud Lindseth, 2004).

A Campanha é um veículo através do qual as autoridades locais têm desenvolvido estratégias para controle das emissões de GEE, e conta com centenas de governos locais espalhados pelo mundo. Tanto governos locais de países desenvolvidos quanto de países em desenvolvimento têm adotado em suas decisões políticas o comprometimento com redução de emissões de GEE.

A Campanha CPC funciona como uma iniciativa para mobilizar as lideranças políticas locais a promoverem esforços para enfrentar o problema das mudanças climáticas e desenvolver políticas públicas sustentáveis. As cidades que aderem ao CPC são encorajados a adotar cinco compromissos (milestones): 1) criação de um inventário de emissões; 2) definição de meta de redução de emissões; 3) desenvolvimento de plano de ação para alcançar a meta; 4) implementação de políticas e medidas para alcançar a meta; 5) monitoramento e verificação de resultados (Betsill e Bulkeley, 2004; Bulkeley e Betsill, 2003).

Em análise da atuação da Campanha CPC nos Estados Unidos, Betsill (2001) encontrou exemplos de ações concretas nos governos subnacionais, principalmente relacionadas à mitigação. Normalmente as ações para mitigação se iniciam nas próprias instalações do governo. Buscam gerar eficiência energética - redução do uso de energia - através de reformas (retrofits) nas instalações do governo, como também nos serviços públicos de iluminação, através da utilização de lâmpadas de LED (light emittint diodes), por exemplo. Promovem compras públicas sustentáveis, estimulando o uso de carros que sejam mais eficientes e menos emissores de GEE, pelos agentes públicos e no transporte público. Buscam estimular o transporte público através de passes especiais que geram economias para os usuários. Promovem também, de modo geral, a recuperação do metano de aterros sanitários com o objetivo de gerar energia, e buscam outras fontes renováveis de energia como solar ou eólica (Betsill, 2001).

Porém, para garantir o engajamento dos atores locais os investimentos em projetos de clima precisam ser justificados pelos ganhos colaterais que garantiriam, tais como economias no orçamento, redução de emissão de poluentes locais, melhoria da qualidade de transportes e melhoria da qualidade de vida. Desse modo, é preciso usar uma abordagem de aprimoramento de projetos já existentes ou criar novos sob a justificativa, não de combate do problema global, mas de ganhos para comunidade local de forma mais imediata (Betsill, 2001; Lindseth, 2004).

Nesse sentido, a abordagem que a Campanha CPC faz para o enfrentamento do problema global das mudanças climáticas é pragmática. Afinal, foca-se na geração de co-benefícios das ações locais convergentes com a redução de GEE, como melhoria da qualidade do ar, qualidade de vida e preocupações com saúde, eficiência energética e poupança de recursos financeiros decorrentes da redução de gastos com energia (Lindseth, 2004). Sendo assim,

[...] em algum momento já não estamos falando de política de mudança climática em si, mas sobre a integração de preocupações com o clima em outros setores da política local, tais como o desenvolvimento de políticas econômicas, ficais e urbanas voltadas para o ordenamento do território, habitação, controle do tráfego, etc. (Lindseth, 2004: 333, tradução nossa).

Além de promover soluções alternativas sobre o enfrentamento das mudanças climáticas globais em nível local, o ICLEI se uniu a um movimento internacional com outras redes de governos locais (United Cities and Local Government, Metropolis, C40 Leadership Climate Group, World Mayors Council on Climate Change), em 2007, durante a Conferência da ONU sobre Mudanças Climáticas em Bali, para a construção de um plano de ação denominado "Bali-Poznan-Copenhagen Roadmap" (Local Government Climate Roadmap, 2011) no qual os militantes dessas redes discutiram um "mapa do caminho" para a proteção climática nas cidades, tanto em mitigação quanto em adaptação. Nessa ocasião, foi lançado um guia de adaptação nas cidades e, desde 
então, o ICLEI tem promovido encontros para tratar da resiliência das cidades ${ }^{1}$.

O Climate Roadmap manifestou o propósito histórico do ICLEI de representar os interesses das cidades no âmbito internacional, demandando mais reconhecimento e autoridade às cidades nas negociações do novo regime climático global do período pós-2012. Tais demandas obtiveram sucesso em 2009. O ICLEI se tornou a primeira rede de governança global autorizada a participar como organização observadora do IPCC (World Bank, 2010: 67). Em 2010, na XVI Conferência das Partes, ocorrida em Cancún (COP16), os governos locais foram reconhecidos oficialmente pela comunidade internacional, pois a delegação do ICLEI foi inclusa nas negociações e foi convidada a dar sugestões para os textos em negociação. Além disso, ao longo do texto assinado na COP16, há menções ao papel dos governos locais no combate às mudanças climáticas.

\section{A Inserção da Agenda Climática no Município de São Paulo}

A cidade de São Paulo criou, em 2001, durante o governo Martha Suplicy (PT), a Secretaria de Relações Internacionais com o objetivo de: 1) assessorar a Prefeitura nas relações institucionais com embaixadas, consulados e representações internacionais de empresas, organizações não-governamentais e universidades, 2) atuar na definição, coordenação e implementação das relações internacionais do município, 3) captar financiamentos e estabelecer acordos de cooperação, parcerias e projetos internacionais. Como resultado da criação dessa Secretaria, a cidade passou a estabelecer vários vínculos com instituições internacionais. Em especial, o município paulistano iniciou uma participação ativa em redes de cidades (Gayard, 2006).

A adesão da cidade à Campanha Cidades para Proteção do Clima do ICLEI ocorreu em 2003, por intermédio da Secretaria do Verde e Meio Ambiente, através da Portaria 35/03, que estabelece um acordo de cooperação técnica da prefeitura com a organização. O teor do acordo de cooperação se resume na implementação da Campanha CPC, visando cumprir os 5 compromissos $^{2}$ e estabelecer coordenação entre

\footnotetext{
Podemos afirmar que o lançamento de um guia de adaptação às mudanças climáticas pelo ICLEI é um marco de uma mudança de abordagem, até então voltada predominantemente à mitigação dos GEE. Cf. ICLEI (2011)

2 São eles: 1) criação de um inventário de emissões; 2) definição de meta de redução de emissões; 3) desenvolvimento de plano de ação para alcançar a meta; 4) implementação de políticas e medidas para alcançar a meta; 5) monitoramento e verificação de resultados.
}

as atividades dos diversos departamentos e órgãos da Prefeitura relacionados à agenda climática, incluindo as áreas de transporte, indústria, energia, gerenciamento de resíduos sólidos, serviços e obras, bem como planejamento urbano (São Paulo, 2003).

Nesse período, a capital paulista era considerada a quinta com ar mais poluído dentre as 20 maiores metrópoles do mundo. A poluição do ar, principalmente decorrente da queima de combustíveis fósseis, além de prejuízos para a saúde e a diminuição da qualidade de vida da população local, emite GEE acirrando o aquecimento global. Tendo isso em vista, o município aderiu a redes geradoras de soluções e alternativas para qualidade ambiental local (Conexão Clima, 2002), tais como: 1) a "Iniciativa do Ar limpo nas Cidades da América Latina" do Grupo Banco Mundial (IAL-CAL) ${ }^{3}$, com a qual foram realizadas uma série de ações para melhoria da qualidade do ar; 2) a Campanha Cidades para a Proteção do Clima do próprio ICLEI, com a qual se iniciou um processo de elaboração de um inventário das emissões de GEE do município (indicador quantitativo no fluxo de problemas), dando cumprimento ao primeiro compromisso de adesão. Ainda em 2003, o governo Martha Suplicy realizou a contratação de uma usina termelétrica para a captação de gás metano ${ }^{4}$ no aterro sanitário Bandeirantes, e, em decorrência, a prefeitura recebeu recursos adicionais provindos do Mecanismo de Desenvolvimento Limpo, instrumento da CQNUMC. Com isso, o município contribuiu para a redução de GEE e simultaneamente gerou melhorias locais e recursos adicionais para a prefeitura (fluxo de soluções e alternativas).

De acordo com Kingdon (2003), o ingresso de uma questão na agenda governamental como um problema que desperta a atenção e esforços de formuladores de políticas ocorre quando há uma junção de três fluxos decisórios distintos e independentes: são eles o fluxo de problemas (problems); fluxo de soluções ou alternativas (policies); e fluxo da dinâmica política (politics).

No âmbito do fluxo dinâmica política, dois fatos ocorridos em 2005 devem ser destacados: 1) no âmbito internacional, houve a entrada em vigor do Protocolo de Quioto com a ratificação pela Rússia, contribuindo assim para gerar um clima favorável na opinião púbica mundial à implementação de políticas climáticas (national mood); 2) no âmbito municipal,

\footnotetext{
${ }^{3}$ A Iniciativa de Ar Limpo nas Cidades da América Latina (IAL-CAL) procura reverter a deteriorização da qualidade do ar nas cidades da região. Cf. World Bank (2011).

${ }^{4}$ equivalente a 21 vezes o $\mathrm{CO} 2$ no seu potencial de aquecimento da atmosfera.
} 
houve a renovação das lideranças políticas no Brasil (turnover). A troca da gestão governamental, segundo Kingdon (2003), possibilitaria a abertura de janelas (policy window) para a mudança ou inserção de problemas na agenda governamental. Nesse contexto, a agenda climática do município não só permaneceu como foi aprofundada. Prova disso é que o prefeito eleito, José Serra (PSDB), já no seu primeiro ano de mandato, deu impulso ao debate sobre a elaboração de uma Lei de Mudança Climática para o Município de São Paulo. De acordo com o secretário do verde e meio ambiente, Eduardo Jorge,

[...] houve outros fatores que contribuíram muito para o engajamento da prefeitura no tema, como os contatos internacionais mantidos via o ICLEI e através da Secretaria de Relações Internacionais, em especial os contatos com agentes do governo da cidade de Londres à época. (Sobrinho apud Biderman, 2011: 245).

Em relação ao fluxo de problemas, o inventário de emissões de gases de efeito estufa do Município de São Paulo foi publicado em 2005 quantificando as emissões de dióxido de carbono $(\mathrm{CO} 2)$ e de metano (CH4) que ocorreram no ano de 2003, decorrentes das atividades sócio-econômicas havidas no Município. Esse inventário atuou como indicador das principais fontes de emissões de GEE do município, e possibilitou conhecimentos capazes de orientar posteriores planos de redução das emissões, bem como a elaboração de projetos para o recebimento de recursos créditos de carbono.

O inventário constatou que as emissões totais no ano de 2003 foram de 15.738.241 GgCO2e. ${ }^{5}$, das quais $99,62 \%$ correspondem aos setores de energia e resíduos sólidos juntos. O setor de energia, por si só, gerou $76,12 \%$ das emissões, enquanto a disposição de resíduos sólidos contribuiu com $23,48 \%$ (São Paulo, 2005).

A questão climática se constituía em um problema incipiente, mesmo na agenda governamental de países desenvolvidos, e principalmente na agenda governamental de governos subnacionais. Por esse motivo, em junho desse mesmo ano, 2005, foi criado o Comitê de Mudanças Climáticas e Ecoeconomia Sustentável pelo decreto 45.959, coordenado pela Secretaria Municipal do Verde e Meio Ambiente, que articulou, no âmbito da prefeitura, oito secretarias e duas empresas prestadoras de serviços municipais, a fim de promover e estimular ações para a mitigação das emissões de gases causadores do efeito estufa

\footnotetext{
5 O símbolo Gg CO2e. representa mil toneladas de Gases de efeito estufa em medida equivalente ao gás carbônico.
}

(fluxo de soluções e alternativas), nas áreas de: I - uso de fontes renováveis de energia; II - aproveitamento do gás metano emitido pelos aterros; III - uso de combustíveis limpos, sobretudo para o transporte público; IV - melhoria da eficiência energética e uso racional de energia; $\mathrm{V}$ - incentivo ao transporte não motorizado; VI - promoção da redução e reciclagem de resíduos; VII - ampliação e aperfeiçoamento do escalonamento dos turnos de trabalho; VIII - ampliação de áreas verdes; IX - estímulo às iniciativas que visem multiplicar as informações atinentes às mudanças climáticas, tais como publicações, páginas na internet, cursos e outras formas de divulgação do assunto (Art. 2). Ou seja, constituiu-se nesse momento uma policy community para gerar soluções de enfrentamento às mudanças climáticas no âmbito local.

Sob o comando de Eduardo Jorge, então secretário municipal da Secretaria do Verde e Meio Ambiente (SVMA), foram realizados debates dos funcionários da prefeitura com especialistas ${ }^{6}$ sobre meio ambiente e mudanças climáticas, representantes de partidos políticos ligados à área ambiental, contatos com outras cidades com alguma experiência no enfrentamento às mudanças do clima em âmbito local e redes transnacionais com programas voltados ao enfrentamento das mudanças climáticas em âmbito local, em especial a Campanha CPC e o C40.

Desde então, sob a coordenação do Comitê de Mudanças Climáticas, uma série de programas em políticas urbanas e ambientais foram estabelecidos e/ou aprofundados, com vistas ao enfrentamento das mudanças climáticas globais e a simultânea co-geração de benefícios econômicos, sociais e ambientais locais (policies).

A seguir apresentamos alguns exemplos de implementação de políticas que ilustram a adesão da agenda climática pelo município de São Paulo em busca de enfrentar o problema global e simultaneamente melhorar a qualidade de vida local e/ou gerar recursos adicionais.

Em relação ao setor de gerenciamento dos resíduos sólidos as principais atividades nesse sentido foram as instalações das usinas de captação de biogás para geração de energia elétrica nos aterros sanitários Bandeirantes, em 2003, e no Sítio São João, em 2005. Tais empreendimentos, além de gerar energia elétrica - a qual é conectada ao sistema de distribuição do município pela empresa AES Eletropaulo -, reduz emissões de GEE devido à queima do metano e recebe recursos provindos do MDL. Ambos empreendimentos

\footnotetext{
${ }^{6}$ Fábio Feldman (militante da área ambiental com grande influência na política brasileira), deputado Fernando Gabeira, Alfredo Sirkis (líder do PV) e Washington Novaes (jornalista da área ambiental).
} 
têm uma vida operacional esperada de 21 anos e, para o primeiro período de obtenção de créditos (7 anos) a quantidade estimada de Reduções Certificadas de Emissão (RCE) é da ordem de 7.494.404 tCO2e no Projeto Bandeirantes e de 5.718.583 tCO2e no Projeto Sítio São João. Os projetos de MDL desses aterros sanitários têm como membros participantes a Prefeitura Municipal de São Paulo, como entidade pública, e a entidade privada Grupo Biogás, sendo que os recursos dos créditos de carbono são divididos em $50 \%$ para cada uma das entidades.

O setor de transportes foi apontado pelo inventário de emissões de São Paulo como o que mais contribui para as emissões de GEE do município. Nesse setor, podemos apontar a principal política para redução de emissões de GEE e melhoria da qualidade do ar local, o Programa de inspeção veicular, implementado em 2007 cujo objetivo é adequar as emissões da frota de veículos do município aos parâmetros recomendados pelo Conselho Nacional de Meio Ambiente (CONAMA) (São Paulo, 2011).

Também em 2005, a Prefeitura lançou o programa compras públicas sustentáveis, baseado nos moldes internacionais do ICLEI, financiado pelo Banco Mundial através do Fundo Mundial para o Meio Ambiente e com o apoio do GTZ (sociedade alemã para cooperação internacional) e coordenação do Centro de Estudos em Sustentabilidade da FGV (Conexão Clima, 2005). A inserção do critério de compras sustentáveis nas licitações da Prefeitura perpassa várias secretarias, para a compra de produtos tais como: madeira legal, papel reciclado, entulho reciclado e combustível na administração municipal etc.

No caso do uso dos solos houve o "programa 100 parques" para expansão de arborização da cidade, incluindo os tradicionais urbanos (parques com áreas de biodiversidade, lazer, cultura), mas também os parques lineares (saneamento, combate a enchentes, reurbanização e lazer) e parques naturais (proteção à biodiversidade). A implantação dos parques lineares propicia a conservação das Áreas de Proteção Permanente (APPs) que margeiam os cursos d'água, ampliam as áreas verdes do município e contribuem para melhorar a permeabilidade do solo, reduzindo assim os riscos de enchentes (medida de adaptação às mudanças climáticas).

Em relação ao setor de energia a Prefeitura assinou um acordo com a Fundação Clinton para se estudar a viabilidade de projetos de melhoria do padrão de consumo energético através de readaptações na iluminação de locais públicos (ruas, parques e prédios públicos). Além disso, em 2007, São Paulo foi a primeira cidade brasileira a tornar obrigatória a instalação do sistema de aquecimento de água por meio do uso de energia solar em novas edificações de prédios residenciais multi-familiares e nos edifícios comerciais que abrigam atividades de comércio, serviços públicos, privados e edificações industriais, através lei 14.459 de 03 de julho de 2007 e do decreto 49.148 de 21 de janeiro de 2008.

Mesmo passando pelo governo de diferentes lideranças, a agenda climática no governo paulistano tem sido mantida e vem se aprofundando. Não foi diferente após a saída de José Serra, em 2006, para concorrer às eleições para governador do Estado de São Paulo. Gilberto Kassab (DEM), que assumiu a Prefeitura, perpetuou o engajamento da cidade em ações climáticas. A participação de Kassab em encontros internacionais das redes de cidades para proteção do clima estimulou ainda mais sua motivação para o enfrentamento das mudanças climáticas, como esclarece Rachel Biderman (2011: 245)

[sua motivação] parece ter sido ainda mais estimulada com a participação do prefeito Gilberto Kassab em Conferência dos prefeitos das 40 maiores cidades do mundo em Nova York em 2007, quando tomou contato com um movimento de políticos que assumiu o desafio de enfrentar as mudanças climáticas mediante aprovação de políticas públicas.

Nessa ocasião, o Prefeito Kassab se comprometeu publicamente em elaborar uma política pública para o enfrentamento do problema em São Paulo. Sendo assim, determinou a seus secretários municipais, sob a liderança de Eduardo Jorge, que formulassem estudos para a criação de uma lei de mudanças do clima para o município.

O processo de formulação da lei ocorreu no âmbito do Programa Ambientes Verdes e Saudáveis (PAVS). Sendo assim, a pedido da Secretaria Municipal do Verde e Meio Ambiente, em março de 2007, se iniciaram os estudos para a elaboração de um anteprojeto de lei sob a coordenação temática do Centro de Estudos em Sustentabilidade (CES) da Fundação Getúlio Vargas (FGV), com o suporte do ICLEI e da SVMA no conteúdo, apoio do Programa das Nações Unidas para o Meio Ambiente (PNUMA), além da participação de várias secretarias municipais e entidades da sociedade civil como, por exemplo, a Fábio Feldmann Consultores, Centro Nacional de Referência em Biomassa e Ambiente Estratégico (Biderman, 2011).

Os estudos para a elaboração do anteprojeto de lei envolveram entrevistas com pesquisadores e especialistas da área de mudanças climáticas, energia e meio ambiente; levantamento sobre o estado da arte da legislação e de políticas subnacionais fora do país; 
revisão da literatura sobre mudanças climáticas; e, mapeamento das medidas que já estavam acontecendo em São Paulo. O processo de levantamento das justificativas técnicas e científicas durou um ano e teve como resultado a minuta da lei em um documento teórico que foi publicado sob a forma de livro pela SVMA $^{7}$ (Biderman, 2011).

O secretário Eduardo Jorge, quando entrevistado sobre o processo de formulação da lei de mudanças climáticas do município, argumentou sobre a importância da experiência prévia na formulação e implementação de políticas com a agenda climática. Além disso, reconheceu o papel do ICLEI e FGV na elaboração da minuta e as vantagens do processo participativo:

[...] no período entre 2005 a 2007 trabalhou-se em exemplos 'dentro da casa` para desencadear debate com a sociedade sobre os temas necessários para criar massa crítica para formulação da lei [Por outro lado, reconheceu a importância] do trabalho feito pela FGV e ICLEI a partir de 2007 na formulação do anteprojeto de lei, e reconheceu a relevância do processo participativo e dos debates promovidos pelas organizações no processo. (Sobrinho apud Biderman, 2011: 246).

Como afirma o secretário do Verde e Meio Ambiente, Eduardo Jorge, em uma fala no Comitê de Mudanças Climáticas: "[...] muita coisa já vinha sendo feita antes da Lei, que intensificou ainda mais esse trabalho." (São Paulo, 2011). Em entrevista, Eduardo Jorge reafirma:

[...] O caminho até a Lei do Clima foi construído gradativamente, com iniciativas palpáveis e que, de fato, contribuíram para que São Paulo fosse reconhecida como pioneira em uma série de ações articuladas de forma intersetorial. A crise ambiental, em especial a questão das mudanças climáticas, é o grande tema do século XXI. A cidade tem proposto políticas e ações com este norte. Principalmente nas áreas de transportes, resíduos, urbanismo, arborização, áreas verdes e adaptação com prevenção de acidentes nas áreas de risco. (Sobrinho, 2011: 10).

Em relação à participação do ICLEI na formulação do anteprojeto de lei, pode-se afirmar que

[...] houve uma forte parceria da prefeitura, através da SVMA, com o ICLEI para a execução de diferentes iniciativas que tornaram possível a elaboração da lei 14.933 [...] A participação do ICLEI na formulação do anteprojeto de lei também tornou possível a utilização de modelos

CF. São Paulo (2009b). e inspiração em boas práticas disseminadas pela rede, em parte incorporadas na lei paulistana. (Biderman, 2011: 132).

A implementação de políticas com agenda climática permitiu um aprendizado político e institucional que subsidiaram a formulação da lei do clima do município. O aprendizado político ocorreu devido a implementação de políticas urbanas e ambientais visando soluções e alternativas locais para o enfrentamento do problema global. E o aprendizado institucional está relacionado a coordenação intersetorial entre as secretarias da Prefeitura para a implementação desta política que é transversal. Além disso, essa experiência possibilitou uma maior conscientização da sociedade civil sobre o problema e sobre como enfrentá-lo em âmbito local.

Dito de outra maneira, a implementação de políticas com agenda climática proporcionou um processo de desenvolvimento institucional baseado em rendimentos crescentes, no qual o aprendizado político ganhou autorreforço para sua ampliação e consolidação (Pierson, 2000).

Pode-se afirmar, portanto, que a política climática é anterior à lei paulistana de mudanças climáticas. Ou seja, a lei foi um corolário das ações que vinham sendo desenvolvidas paulatinamente em consonância com a agenda climática. Nesse sentido, a lei 14.933, de 05 de junho de 2009, intitulada Política de Mudança do Clima no Município de São Paulo, pode ser considerada como o corolário da implementação de uma série de políticas urbanas e ambientais que vinham sendo empreendidas pela Prefeitura desde 2003. (São Paulo, 2009a)

\section{Considerações Finais}

Entendendo o papel das áreas urbanas no enfrentamento às mudanças climáticas, várias redes transnacionais de governos locais começaram a se formar em torno dessa questão, com vistas a inserir a questão climática na agenda decisional de governos subnacionais.

De modo geral as redes transnacionais de governos locais com ações voltadas à proteção do clima, e, em particular a Campanha Cidades para Proteção do Clima do ICLEI, buscam sensibilizar as lideranças locais para o problema global das mudanças climáticas apresentando alternativas e soluções que prevêem a geração de co-benefícios locais como aumento na qualidade de vida, qualidade ambiental, economia de energia e recursos e a geração de recursos adicionais. Assim buscam fomentar a introdução da questão climática na agenda governamental.

A adesão do município de São Paulo à Campanha CPC teve como conseqüência a elaboração de um inventário de emissões de GEE do município, em 2005. Este contribuiu como indicador quantitativo 
sobre os problemas e oportunidades relacionadas à questão climática no município. Além disso, no mesmo ano, vários fatores convergiram para a junção (coupling) dos fluxos (problems, policies, politcs) e a ampliação da inserção do problema climático na agenda governamental do município: a mudança de gestão governamental (ciclo político) no município abriu uma oportunidade (policy window) de mudanças e inserção de problemas na agenda governamental; a entrada em vigor do Protocolo de Quioto com a ratificação pela Rússia contribuiu para gerar um clima favorável na opinião púbica mundial à implementação de políticas climáticas (politics stream); a experiência com a captação de gás metano para geração de energia no aterro Bandeirantes com recursos provindos do MDL gerou expectativas de recursos adicionais (policy stream).

De 2005 a 2007, o município empreendeu ações políticas com interface no enfrentamento às causas e conseqüências locais das mudanças climáticas. Tais políticas foram conduzidas pelo Comitê de Mudanças Climáticas criado em 2005, sob a liderança do secretário do Verde e Meio Ambiente, Eduardo Jorge. A formulação dessas políticas teve, em boa medida, a inspiração de boas práticas difundidas pela campanha CPC do ICLEI e pela rede C40.

A adesão das lideranças políticas de governos locais às redes transnacionais de governos locais voltados à proteção do clima, sua participação nos encontros, bem como seu comprometimento, ainda que discursivo, com tais redes, contribui como fonte de motivação e inspiração para a inserção da questão climática em suas agendas governamentais.

\section{Referências}

Betsill, Michele e Bulkeley, Harriet. 2007. Looking back and thinking ahead a decade of cities and climate change research. Local Environment, 12(5): 447-456. http://dx.doi.org/10.1080/13549830701659683

Betsill, Michele e Bulkeley, Harriet. 2006. Cities and the multilevel governance of global climate change. Global Governance, 12: 141-159.

Betsill, Michele e Bulkeley, Harriet. 2004. Transnational networks and global environmental governance: the cities for climate protection program. International Studies Quarterly, 48: 471-493. http://dx.doi. org/10.1111/j.0020-8833.2004.00310.x

Betsill, Michele. 2001. Mitigating climate change in US cities: opportunities and obstacles. Local Environment, 6(4): 393-406. http://dx.doi. org/10.1080/13549830120091699

Biderman, Rachel. 2011. Limites e alcances da participação pública na implementação de políticas subnacionais em Mudanças Climáticas e o Município de São Paulo. Tese (Doutorado em Administração Pública e Governo), Escola de Administração de Empresas de São Paulo, Fundação Getúlio Vargas.
Bulkeley, Hariet e Betsill, Michele. 2003. Cities and climate change: urban sustainability and global environmental Governance. New York: Routledge.

C40 Cities. Climate leadership group. Disponível em: <http://www.c40cities.org/>. Acesso em: 30 jul. 2011.

Climate Alliance. 2011. Disponível em: <http://www. climatealliance.org/>. Acesso em: 29 jul. 2011.

Conexão Clima: ação local contra o aquecimento global, 1(1): 9-11. 2002

Conexão Clima: ação local contra o aquecimento global, 4(4). 2005.

Gayard, Nicole Aguiar. 2006. Paradiplomacia na Cidade de São Paulo: Uma Análise Empírica da Inserção Internacional do Município. In: T. Vigevani (Coor.), Gestão pública e inserção internacional das cidades, relatório científico: centro de estudos de cultura contemporânea (CEDEC). São Paulo: PUC-SP; UNESP e FGV-SP.

Kern, Kristine e Bulkeley, Hariet. 2009. Cities, europization and multi-level governance; governing climate change through transnational municipal network. Wiley Online library, 47(2): 309-332.

Kingdon, John. 2003. Agendas, alternatives, and public policies. 3rd ed. Nova York: Harper Collins.

Lindseth, Gard. 2004. The cities for climate protection campaign (CCPC) and the framing of local climate policy. Local Environment, 9(4): 325-336. http:// dx.doi.org/10.1080/1354983042000246252

Local Government Climate Roadmap. 2011. Disponível em: <http://www.iclei.org/index.php?id=climateroadmap >. Acesso em: 29 jul. 2011.

ICLEI. Local Governments For Sustainability. 2011. Programs. Disponível em: <http://www.iclei.org/ index.php?id=10832>. Acesso em: 29 jul. 2011.

Internacional Solar Cities Initiative - ISCI. 2011. Disponível em: <http://www.isci-cities.org/>. Acesso em: 29 jul. 2011.

Martins, D'Almeida Rafael e Ferreira, Leila da Costa. 2011. Opportunities and constraints for local and subnational climate change policy in urban areas: insights from diverse contexts. Global Environmental Issues, 11(1): 37-53. http://dx.doi.org/10.1504/ IJGENVI.2011.040250

Ostrom, Elinor. 2010. A Polycentric approach for coping with climate change. Report prepared for the World Bank's world development: development in a changing climate. Disponível em: <http://www-137 wds.worldbank.org/servlet/WDSContentServer/ WDSP/IB/2009/10/26/000158349_20091026142 624/Rendered/PDF/WPS5095.pdf>. Acesso em: 15 mar. 2011.

Pierson, Paul. 2000. Increasing returns, path dependence, and the study of politics, The American Political Science Review, 94(2): 225-267. http://dx.doi. org/10.2307/2586011

Rhodes, Roderick Arthur William. 2008. Policy network analysis. In: R. E. Goodin, M. Rein e M. Moran (Ed.). The Oxford Handbooks of Political Science. Oxford Handbooks, p. 425-447. PMid:18842458. 
São Paulo (Município). Secretaria municipal do verde e meio ambiente. 2003. Portaria $n^{\circ} 35$ de adesão do Município de São Paulo, por intermédio da Secretaria Municipal do Verde e do Meio Ambiente - SVMA, à Campanha "Cidades Pela Proteção do Clima CСРТM" pela celebração do Acordo de Cooperação Técnica no. 11/3. Diário Oficial do Município de São Paulo, São Paulo, 15 abr. 2003. Disponível em: <http://www3.prefeitura.sp.gov.br/cadlem/ secretarias/negocios_juridicos/cadlem/integra.asp? alt $=25042003 \mathrm{P} \% 20000352003$ SVMA $\% 20 \% 20 \% 20$ $\% 20 \% 20 \% 20 \% 20 \% 20 \&$ secr $=87 \&$ depto $=0 \&$ descr tipo=PORTARIA $>$. Acesso em: 15 out. 2011.

São Paulo (Município). Secretaria Municipal do Verde e do Meio Ambiente. 2005. Inventário de emissões de gases de efeito estufa do município de São Paulo. São Paulo: Centro Clima/COPPE/UFRJ, 2005.

São Paulo (Município). 2009a. Lei no 14.933, de 5 de junho de 2009. Institui a Política de Mudança do Clima no Município de São Paulo. Diário Oficial do Município de São Paulo, São Paulo, 06 jun. Disponível em: <www.leismunicipais.com.br>. Acesso em: 01 out. 2010.

São Paulo (Município). 2009b. Exposição de motivos: política municipal de mudanças climáticas para São Paulo. Barueri: Minha Ed. (Coleção ambientes verdes e saudáveis, n. 3). Disponível em: <http:// www.iee.usp.br/biblioteca/producao/2009/Livros/ LivroexposicaodemotivosSite.pdf>. Acesso em: 10 out. 2010.

São Paulo (Município). Secretaria Municipal do Verde e do Meio Ambiente. Programas e projetos. Disponível em: <http://www.prefeitura.sp.gov.br/cidade/ secretarias/meio_ambiente/programas_e_projetos/ index.php?p=7833>. Acesso em: jun. 2011.

São Paulo (Município). Comitê Municipal de Mudança do Clima e Ecoeconomia. 2011. Ata da $21^{a}$ reunião do comitê municipal de mudança do clima e ecoeconomia. São Paulo, Reunião do Comitê Municipal de Mudança do Clima e Ecoeconomia. Disponível em: <http:// www.google.com.br/url?sa=t\&rct=j\&q=ata $\% 20$ da $\% 2021 \% \mathrm{C} 2 \%$ A A $\% 20$ reuni $\%$ C $3 \%$ A $30 \% 20$ do\%20comit $\%$ C3\%AA\%20municipal $\% 20 \mathrm{de} \% 20$ mudan $\%$ C $3 \%$ A 7a $\% 20$ do $\% 20$ clima $\% 20$ e $\% 20$ ecoeconomia $\% 20 \&$ source $=$ web $\& c d=1 \&$ ved $=0 C C$ MQFjAA\&url=http $\% 3 \mathrm{~A} \% 2 \mathrm{~F} \% 2 \mathrm{Fwww}$.prefeitura. sp.gov.br $\% 2$ Fcidade $\% 2$ Fsecretarias $\% 2$ Fupload $\% 2$ Fchamadas\%2FATA_1_REUNIAO_1267031477. doc\&ei=UX-QT4fhKIruggfE0-DjBA\&usg=AFQj CNGQ1pEueszcZKik43pA3BS5WijaTw>. Acesso em: 15 out. 2011.

Satterthwaite, James. 2008. Climate Change and Urbanization: Effects and Implications for Urban Governance. New York, United Nations Expert Group Meeting on Population Distribution, Urbanization, Internal Migration and Development. UN/POP/ EGMURB/2008/16.
Sobrinho, Eduardo Jorge. 2011. Diretrizes para o Plano de Ação da Cidade de São Paulo para Mitigação e Adaptação às Mudanças Climáticas. 2011. Secretário do Verde e do Meio Ambiente. Disponível em: $<$ http://www.prefeitura.sp.gov.br/cidade/secretarias/ upload/chamadas/diretrizes_clima_bilingue_ julho_2011_low_1310480805.pdf 2011>. Acesso em: 15 out. 2011.

Toly, Noah. 2008. Transnational municipal networks in climate politics: from global governance to global politics. Globalizations, 5(3): 341-356. http://dx.doi. org/10.1080/14747730802252479

United Cities And Local Governments - UCLG. 2011. Disponível em: <http://www.cities-localgovernments. org/sections.asp>. Acesso em: 25 abr. 2011.

United Nations Human Settlements Programme - Un-Habitat. 2011. Cities and climate change: policy directions. Global report on human settlements. Disponível em: <http://www.unhabitat. org/downloads/docs/GRHS2011/GRHS.2011. Abridged.English.pdf>. Acesso em: 20 maio 2011.

Van Staden, Marike. 2010. Motivation for action. In: M. Van Staden e F. Musco (orgs.), Local government and climate change: sustainable energy planning and implementation in small and medium sized communities. New York: Springer, p. 16-30.

Vargas, Marcelo e Rodrigues, Diego Freitas. 2009. Regime internacional de mudanças climáticas e cooperação descentralizada: o papel das grandes cidades nas políticas de adaptação e mitigação. In: D. J. Hogan e E. Marandola Junior (Ed.). 2009. População e mudança climática: dimensões humanas das mudanças ambientais globais. Campinas: Ed. UNICAMP, p. 205-222.

Viola, Eduardo. 2002. O regime internacional de mudança climática e o Brasil. Revista brasileira de ciências sociais, 17(50).

World Mayors Council for climate Change - WMCCC. 2011. Disponível em: <http:// www.worldmayorscouncil.org/>. Acesso em: 25 maio 2011.

World Bank. 2010. Cities and climate change: an urgent agenda. Washington: Urban Development \& Local Government, v. 10. Disponível em: $<$ http://siteresources.worldbank.org/INTUWM/ Res ources / 340232 - 1205330656272 / CitiesandClimateChange.pdf $>$. Acesso em: 25 maio 2011.

World Bank. 2011. Iniciativa Ar Limpo nas Cidades da América Latina. Disponível em: <http:// web.worldbank.org/WBSITE/EXTERNAL/ H O M E P O R T U G U E S E / EX T PA I S E S / EXTLACINPOR/BRAZILINPOREXTN/0,,conte ntMDK:21372524 menuPK:3885041 pagePK:14 1137 piPK:141127 theSitePK:3817167,00.html>. Acesso em: 11 nov. 2011. 